\section{The Irony of Satire}

April 2009 212-231

(C) 2009 SAGE Publications

$10.1177 / 1940161208330904$

http://ijpp.sagepub.com

Political Ideology and the Motivation

to See What You Want to See

in The Colbert Report

\author{
Heather L. LaMarre \\ Kristen D. Landreville \\ Michael A. Beam \\ The Ohio State University
}

This study investigated biased message processing of political satire in The Colbert Report and the influence of political ideology on perceptions of Stephen Colbert. Results indicate that political ideology influences biased processing of ambiguous political messages and source in late-night comedy. Using data from an experiment $(N=332)$, we found that individual-level political ideology significantly predicted perceptions of Colbert's political ideology. Additionally, there was no significant difference between the groups in thinking Colbert was funny, but conservatives were more likely to report that Colbert only pretends to be joking and genuinely meant what he said while liberals were more likely to report that Colbert used satire and was not serious when offering political statements. Conservatism also significantly predicted perceptions that Colbert disliked liberalism. Finally, a post hoc analysis revealed that perceptions of Colbert's political opinions fully mediated the relationship between political ideology and individual-level opinion.

Keywords: political entertainment; comedy; satire; political ideology; information processing

$I^{n}$ $\mathrm{n}$ recent years, there has been a surge of political entertainment studies within mass communication. These studies have demonstrated a series of effects of political entertainment on individual-level socio-political attitudes related to a variety of political issues (e.g., women's rights, Holbert et al. 2003; capital punishment and gun ownership, Holbert et al. 2004), as well as a strong set of relationships between late-night comedy and individual-level political attitudes and behaviors (e.g., Young and Tisinger 2006). Late-night comedy studies have demonstrated significant effects ranging from primacy and recency (Holbert et al. 2007) to acquisition of political

Authors' note: Address correspondence to Heather L. LaMarre, PhD, School of Journalism and Mass Communication, 111 Murphy Hall, 206 Church Street S.E., Minneapolis, MN 55455; e-mail: HLaMarre@ gmail.com. 
knowledge (e.g., Young 2008). Such findings are consistent with political entertainment research, which demonstrate the influence of prime-time television on individual-level political perceptions, attitudes, opinions, and behaviors (e.g., Delli Carpini and Williams 1994; Holbrook and Hill 2005).

While considerable attention has been paid to effects of consuming late-night political comedy television (e.g., Young 2004) little empirical research has examined the underlying processes and mechanisms (Young 2008). Using the satirical political comedy of Stephen Colbert (The Colbert Report), this study extends beyond political entertainment effects studies and examines how audiences process political messages found in late-night political satire.

Recent work in social psychology demonstrates that individuals process information in ways that personally benefit them and that people tend to see what they want to see when the information is ambiguous (e.g., Balcetis and Dunning 2006; Kunda 1990; Long and Toppino 2004). Because satire is often ambiguous, biased information processing models provide an excellent framework for understanding how audiences see what they want to see in Colbert's political satire. As such, the present study uses ambiguous message processing theory (Balcetis and Dunning 2006) to address two core questions: (1) what role does individual-level political ideology play in processing political satire, and (2) are individuals driven by in-group favoritism or a similar need to reinforce the favorable status of their political group to "see what they want to see in political satire?" Taken together, these questions raise the possibility that individuals, motivated by their needs for political affiliation and self-enhancement, engage in biased processing of political messages offered in ambiguous form (i.e., deadpan satire or parody). What follows is an overview of these concepts and ideas, results of an online survey with an embedded clip of Stephen Colbert, and a discussion of the findings and their implications for political entertainment research.

\section{Party Identity and Need for Affiliation}

Party affiliation and political ideology have long been recognized in the literature as key variables for predicting a wide range of political attitudes and behaviors (Campbell et al. 1960; Carsey and Layman 2006; Kenski and Stroud 2004).The majority of studies involving political affiliation and ideology conceptualize these characteristics as individual difference variables that are attributed to political socialization and a core set of political beliefs, respectively (see Campbell et al. 1960). However, this study reconceptualizes party identification and political ideology as a form of the social self using Brewer's (1991) concept of optimal distinctiveness. According to this theory, people maintain their social self, in part, by balancing their need to assimilate while also remaining distinct from groups.

Brewer (1991) argues that social identity and group loyalty are strongest for groups that allow individuals to reconcile these competing needs. Political parties are good examples of groups whose umbrellas are large enough to fill this tall order. 
For example, political parties allow for individuals or groups who hold similar political ideas and beliefs to strategically align, which satisfies one's need for assimilation. On the other hand, major political parties such as the Republicans and Democrats are comprised of diverse subgroups and individuals with distinct political goals and agendas (see Beck 1992 for an overview). This conglomeration of very different groups with common political affiliation permits individuals to both assimilate and remain distinct (an optimal condition under Brewer's model). From this perspective, political party affiliation is understood as a means by which individuals can fulfill the competing needs of the social self. By extension, individuals with strong political ideologies (e.g., very liberal or very conservative) will view groups who share these values and beliefs as an important part of their social self (Tajfel and Turner 1986). The question then becomes whether they actively engage in groupenhancing behaviors as a means of maintaining their social self. Stated differently, individuals with strong political ideologies may be motivated by their social self (as defined by Brewer 1991) to process ambiguous information in a way that favors their political beliefs and/or political groups who hold similar beliefs and opinions.

\section{Ambiguity and Biased Information Processing}

Building on Bem's (1972) self-perception theory, several key studies have shown that people process ambiguous information in ways that favor themselves (e.g., Balcetis and Dunning 2006; Kunda 1990; Long and Toppino 2004). Additionally, self-enhancing behaviors, which include biased information processing, have been linked to individuals' motivation to bolster, maintain, or restore the self (e.g., Festinger 1957; Leary and Baumeister 2000). Taken together, it is clear that individuals actively seek out ways to maintain a favorable opinion of the self. As previously suggested, this motivation toward self-enhancement should extend to the social self, which would likely manifest as a need to view groups that comprise the social identity as favorable (see Brewer 1991 for a review).

Recent evidence of individuals' self-favoring processing of ambiguous information also suggests that such processing is precognitive, further pointing to an underlying motivation at work. Balcetis and Dunning (2006) exposed participants to ambiguous figures (which could be interpreted as a seal or horse for one figure and either the letter B or the number thirteen for the other figure). They used various experimental manipulations that would result in either positive or negative consequences for the participants depending on how they interpreted the information. The results indicated that participants would process the information in ways that brought about rewards or avoided punishments. The researchers also concluded that this occurred precognitively such that participants were not even aware of their own bias. The major conclusion drawn from this research was that people were motivated by their need for self-enhancement (e.g., desire to affirm one's own political beliefs) to process the information in a manner favorable to the self. 
Additionally, Hovland's (1951) learning theory also outlined conditions for biased processing. Hovland argued that, when distraction, low comprehension, or other motivations (e.g., to affirm one's own political ideas as correct) intervene with message processing, it is likely that bias or error will occur. If external cues cannot be used to aid in information processing, internal cues become the predominant means by which the information is interpreted. Taken together, Hovland (1951) and Balcetis and Dunning (2006) outline a set of conditions under which people are likely to engage in biased processing that results in self-favoring interpretations of information. As outlined below, we argue that Stephen Colbert's deadpan political satire meets these conditions as it offers ambiguous political messages from an ambiguous political source through late-night entertainment television to audiences who primarily expect to be entertained.

One might argue that all media are subject to differences in individual-level perceptions, suggesting that extant literature has shown that individual-level differences influence the way media are perceived across a variety of forms and contexts (e.g., McLeod et al. 2002; Shrum 2002). Much of this work, however, deals with issues related to perceived reality (Busselle and Greenberg 2000; Shrum 2002), hostile media perceptions (Vallone et al. 1985) or differences in interpretations that do not necessarily result in self-favoring interpretations (McLeod et al. 2002). In contrast, biased processing concerns itself with a type of precognitive, unintentional information processing that occurs as a means of creating self-enhancing benefits. Thus, with biased processing individuals actually see and hear different information depending on whether that information will help or hinder their personal goals and needs. Stated differently, biased processing goes beyond perceptions of whether the entertainment was realistic (e.g., Busselle and Greenberg 2000) or whether the media treated one side more fairly than the other (e.g., hostile media effect) to an underlying cognitive process in which the information is interpreted, encoded, stored, and retrieved in a manner that most benefits that individual. The importance of understanding the role of biased processing becomes evident when thinking about the potential effects such processes have on attitudes and opinions. If, for example, two people with opposing political viewpoints interpret the same information as favoring their own political opinions, then polarization can occur. Additionally, when the source is also interpreted by each individual as favoring their side, then the source itself becomes a polarizing agent. In essence, we argue that biased processing of ambiguous political messages and sources such as those found in certain types of satire leads to polarization among the electorate as well as serving as the basis for which people form future judgments and attitudes offered by the ambiguous source.

\section{Satire as Ambiguous Political Messages}

Satire is described as a playful distortion of reality (Feinberg 1967). Young (2006, 2008) found that the satire used in late-night political comedy was an ambiguous 
form of comedy that required audiences to apply cognitive effort in processing the jokes. Baym (2005) offered a qualitative understanding of how people negotiate this ambiguity arguing that The Daily Show host Jon Stewart provides context for viewers as he interjects commentary during segments, moves in and out of character, and even laughs at himself. From this perspective, it becomes clear that while the satirical messages themselves are ambiguous, Stewart aids viewer interpretation by offering himself as an unambiguous source and providing external cues (Baym 2005; Young 2006; Young and Tisinger 2006). In contrast, we outline below how Colbert's deadpan satire and commitment to character do not provide viewers with the external cues or source recognition that Stewart offers. Thus, Colbert creates conditions under which biased processing is likely to occur.

In addition to Young's work on late-night comedy and political messages, a key media that focused on multiple perceptions of television characters was Vidmar and Rokeach's (1974) study of the hit 1970s primetime series All in the Family. This study examined whether audiences would interpret the lead character, a parodied bigot named Archie Bunker, as a negative role-model. The study found that individuals who identified with the character's conservative nature and agreed with his political views held favorable perceptions of the character and believed Archie Bunker articulated legitimate viewpoints. However, individuals with low character identification and opposing political views held unfavorable perceptions. Of particular interest in this study is that individuals who identified with Bunker's sociopolitical views were not influenced by the director's negative framing of the character, while those who did not identify with Bunker's political viewpoint reported attitudes and perceptions consistent with the negative framing of this television character. Clearly, individual-level political beliefs have the potential to bias the way audiences perceive information and mitigate attempts to frame characters and information in particular ways. While this study provided an early look at satire and parody's role in processing ambiguous political messages in entertainment television, Vidmar and Rokeach's (1974) study did not differentiate between individual-level perceptions that can occur in many types of media information processing (e.g., McLeod et al. 2002; Shrum 2002) and the specific type of biased processing that occurs when information is both ambiguous and lacking context (e.g., Balcetis and Dunning 2006; Long and Toppino 2004). This study focuses on the latter and extends our knowledge of how certain forms of satire such as deadpan create the conditions under which biased processing and self-favoring perceptions are likely to result.

\section{Stephen Colbert's Deadpan Satire as Ambiguous Political Source}

Recently, an extreme form of satire, known as deadpan, has drawn large audiences in late-night comedy. Although The Colbert Report is not the first use of deadpan satire in entertainment media (e.g., Vidmar and Rokeach 1974), it is of particular 
relevance to understanding the intersection of political entertainment and motivated message processing, offering an excellent context of study. Colbert relies on deadpan, a specific type of satire that uses a straight-faced approach to joke telling. In contrast to The Daily Show's Jon Stewart, Stephen Colbert rarely breaks character and maintains a level of seriousness as he parodies conservative pundits (LaMarre and McCluskey 2007). This extreme form of deadpan increases the ambiguity of the source, as well as the message and fails to offer viewers external cues for information processing. Source ambiguity requires the audience to participate in determining whether the source is sincere (Simpson 2003). While audiences may be aware that the source is using humor, they must still make a judgment of whether Colbert's underlying meaning is sincere. In essence, deadpan satire forces the message recipients to not only judge the intended meaning of the message, but also evaluate the sincerity of the source. Often the satirist assumes that the audience will correctly interpret the satirist's poker-faced delivery and comprehend the deep sarcasm being used. However, studies show that audiences struggle with deadpan and other forms of satire, which have been associated with miscues and errors among message recipients (e.g., Feinberg 1967; Pfaff and Gibbs 1997; Simpson 2003). That is, when the audience judges the satirist to be sincere, then the statements the satirist makes are judged as representing the satirist's true beliefs. What results is a situation where the audience member misidentifies the satirist's beliefs and intentions. Because high levels of cognitive effort are required to determine the satirist's intention and true meaning, it makes satirical uptake a complicated process (e.g., Baym 2005; Feinberg 1967; Simpson 2003; Young 2008;). Coupling this complex process within an entertainment setting where people are generally less engaged in effortful cognitive processing of political information (Young 2006; Young and Tisinger 2006), conditions for miscues and biased processing emerge.

For example, if an individual simply does not comprehend the satire as Colbert intended, then the message might be processed, stored in memory, and later recalled at face value or in some biased manner. We argue that this would be more likely to occur if the person's political beliefs and/or affiliations are consistent with the statements made at face value as opposed to a negated and re-interpreted translation of the message normally required for processing deadpan satire. In a recent content analysis of Stephen Colbert's show host persona, LaMarre and McCluskey (2007) found that Colbert parodies a conservative political pundit who makes socially conservative, authoritative, and aggressive statements toward out groups. Thus, a biased or errant interpretation of his statements would be consistent with political and social conservatism, while a negated interpretation of the satire would suggest something quite different. Considering the above arguments, we expect that political conservatives are significantly more likely than liberals to interpret Colbert's statements as pro-conservative and/or targeting liberalism. 


\section{Contextual Example}

A recent example of Colbert's deadpan occurred when the host interviewed CNN News Anchor Anderson Cooper about global warming on October, 18, 2007 (ComedyCentral.com 2007). During the interview, Colbert asked a series of questions in his deadpan style such as "What's wrong with the ice melting . . . maybe now Greenland will actually turn green." Notably, serious arguments relating to Greenland returning to its former state as a green, nontundra condition as a positive outcome have been offered by conservative political talk show host Rush Limbaugh (RushLimbaugh.com 2008). Colbert concluded with the question, "What can a person like me do to help that will in no way inconvenience me?" Clearly these comments are somewhat ambiguous and open to multiple interpretations. If Colbert offered himself as a source with a clear, unambiguous position, then viewers would have external cues guide their interpretation of the statements. However, Colbert's deadpan leaves open the question of who he is targeting and what he really means. Is Colbert parodying the global warming opponent or is he using satire to ridicule the global warming activist? We argue that when faced with this type of ambiguity, viewers will see what they want to see in this situation. In short, people will likely see such comments as funny, but will perceive the joke to be on the opposition and perceive Colbert in the manner that comports with their own political belief system, serving to reinforce and possibly even strengthen their own attitudes. Overall, this contextual example of Colbert's satirical commentary on global warming demonstrates the potential for biased processing in a manner that favors one's own political beliefs or groups closely identified with these beliefs, resulting in further polarization among the electorate.

\section{Synthesis and Hypotheses}

To this point, we have examined how ambiguity in late-night political satire such as the deadpan style offered by Stephen Colbert creates conditions under which biased processing is likely to occur. We predict that the absence of external cues (e.g., ambiguous source) coupled with the entertainment setting (e.g., parody and satire) will result in biased processing of ambiguous political messages wherein individuals will interpret Colbert's statements and perceive his intended meaning in ways that support their personal political beliefs and affiliations. This is formally hypothesized as follows:

Hypothesis 1: Individual-level political conservatism positively predicts perceptions that Colbert genuinely means what he says when offering satirical political statements.

Additionally, we argued that Colbert's commitment to character as a conservative political pundit and deadpan style create ambiguity regarding his personal political beliefs, affiliations, and attitudes toward the liberal ideas and beliefs that his 
statements target (LaMarre and McCluskey 2007). Considering the biased processing we previously outlined, we predict that viewers will interpret Colbert's personal political beliefs, party affiliation, and attitudes toward liberals in a manner consistent with their own political beliefs. More formally, we hypothesize the following:

Hypothesis 2: Individual-level political conservatism positively predicts perceptions of Colbert as personally politically conservative.

Hypothesis 3: Individual-level political conservatism positively predicts perceptions of Colbert as having a political affiliation that is Republican.

Hypothesis 4: Individual-level conservatism positively predicts perceptions that Colbert personally dislikes political liberalism.

Considering that The Colbert Report is a comedy program run on a comedy station, it is important to determine whether biased processing completely negates the perception of humor among those who think he genuinely means what he says (e.g., strong political conservatives) or simply alters their perception of who the joke targets are. As such, one lingering question is whether biased processing impacts perceptions of humor. Stated differently, it is unknown whether conservatives who engage in biased processing fail to see the humor at all (e.g., do not perceive Colbert as funny). Simpson (2003) argues that people are less likely to think satire is funny when they think it is inappropriate (such as unfairly targeting someone). However, biased processing should result in both sides perceiving the satire as fairly targeting the opposing political viewpoint. Therefore, the inappropriateness issue should not come into play. Because there is little extant literature to shed light on this question we offer the following research question aimed at determining whether both sides think Colbert is equally funny:

Research Question 1: Does political conservatism negatively predict perceptions that Colbert is funny?

\section{Method}

\section{Participants and Procedure}

The data presented in this study were collected in an online survey from 332 participants enrolled in undergraduate communication courses at a large midwestern university. Participants were 58 percent female and 42 percent male, ranging from ages 18 to 40 $(M=21, S D=2.23$. Participants were primarily white ( 85 percent) with a small number of African-American (5 percent), Asian American (4 percent), and other ethnicities (6 percent). Only 15.1 percent reported "Democrat" and 13.8 percent reported "Republican," while the remaining 71.1 percent either reported being "Independent" (68.3 percent), "Other" ( 2.2 percent), or "decline to answer" ( 0.6 percent). 
Participants were recruited from several large undergraduate communication courses and were offered extra credit in their courses for participation in the study. If students were interested in participating in the study, they were directed to the online survey by means of the various course Web sites. Questions about participants' exposure to political entertainment and perceptions about Stephen Colbert's political party affiliation and ideology were asked before showing a video clip from The Colbert Report, described later. Then, participants viewed the video clip. After viewing the clip, participants were asked if they were able to see and hear the entire embedded video clip. If the participant reported they could not see or hear the video clip, most likely due to the lack of playback software or computer speakers, they were redirected to an alternate study $(N=72)$. The 332 participants reported in this study responded in the affirmative that they did see and hear the entire video clip. After the video clip, a series of questions about perceptions of Stephen Colbert were asked (e.g., credibility of Colbert's opinion, perception of Colbert's political ideology, seriousness of Colbert's opinion), as well as demographic questions. It is important to note the dependent variable measures were asked in a random order to avoid order effects (see Tourangeau et al. 2000). Finally, participants were thanked when completing the survey and given extra credit in exchange for their participation.

\section{Stimulus}

As mentioned above, this study operationalized deadpan satire using Stephen Colbert's character in The Colbert Report. Participants viewed a three-minute online video clip containing Colbert interviewing liberal talk radio host Amy Goodman from Democracy Now! (ComedyCentral.com 2006). In the clip, Colbert introduces Goodman as a "super liberal lefty." Goodman claims the Iraq war is breaking down the conservative and liberal lines. Colbert claims the conservatives are "right" and the liberals are "wrong." After this, Goodman discusses the benefit of un-embedded reporting through findings from interviews with thousands of American Iraq War troops and veterans that show a majority of support for withdrawing from the war. Colbert again criticizes her assessment commenting that her sample was "un-scientific" and that thousands of troops are satisfied and support the use of embedded journalists. Goodman criticizes the quality of journalism found in the mainstream news from embedded reporting. Colbert argues embedded reporting is successful because reporters working with troops have more knowledge of the situation on the ground.

\section{Measures}

Self-reported political ideology. Political ideology, the independent variable in the hypotheses, was measured using a single-item, self-report measure. Participants were asked "Now thinking in terms of political issues, would you say you are: Very Liberal, Liberal, Somewhat Liberal, Moderate, Somewhat Conservative, Conservative, 
Very Conservative, or don't know?" The responses were coded 1-7, respectively $(M=3.68, S D=1.48)$.

Perceptions of Colbert's statements. Hypothesis 1 focuses on how respondents interpreted and processed Colbert's statements. Perceptions that Colbert was using humor but actually meant to target liberals was assessed using a three-item index $(r=.73)$. Participants could "Strongly Disagree," "Disagree," feel "Neutral," "Agree," or "Strongly Agree," that "in the video clip Colbert means what he says about liberal groups like Democracy Now," coded 1-5 $(M=3.13, S D=1.05)$, "in the video clip Stephen Colbert pretends to be joking but really means what he says about liberals being wrong and conservatives being right" $(M=3.06, S D=1.13)$, and "in the video clip Colbert uses satire and is not serious at all" (reverse coded $M=3.26, S D=1.13$ ).

Perceived political ideology and affiliation of Stephen Colbert. Colbert's political ideology, the dependent variable in Hypothesis 2, was tested by asking participants to "Strongly Disagree," "Disagree," feel "Neutral," "Agree," or "Strongly Agree" in response to the statement "Stephen Colbert is socially conservative, coded 1-5 ( $M=$ 2.99, $S D=1.08$ ). Political party affiliation, tested in Hypothesis 3, was assessed by the participants' strongly disagree to strongly agree response to the statement, "Stephen Colbert is a Republican." The responses were again coded $1-5$, as in Hypothesis $2(\mathrm{M}=2.99, S D=1.17)$.

Perceptions of Colbert's personal attitude toward liberalism. We measured individual-level perceptions of Colbert's personal opinion regarding the liberals he targets in his statement using a five-point two-item index (zero-order $r=.81$ ) from strongly disagree to strongly agree. Participants were asked to strongly agree, agree, feel neutral about, disagree, or strongly disagree with the following two statements: "Stephen Colbert personally does not like liberal groups like Democracy Now" coded 1-5 ( $M=$ $3.58, S D=1.01$ ) and "Stephen Colbert personally agrees with liberal ideas and opinions like those offered by his guest" reverse coded $(M=3.36, S D=1.04)$.

Perception of Colbert as humorous. We used a single five-point item (strongly disagree to strongly agree) to measure perceptions that Colbert is funny: "I thought Colbert was funny in the video clip" $(M=2.89, S D=1.14)$.

\section{Analysis}

OLS regressions were used to test the four hypotheses and one research question. The first regression (Hypothesis 1) predicted perceptions of Colbert's seriousness from individual-level political ideology. The next two hypotheses (Hypothesis 2, Hypothesis 3) predicted perceptions of Colbert's political ideology and political party affiliation 
from individual-level political ideology. The final hypothesis (Hypothesis 4) predicted perception of whether Colbert liked/disliked liberals from political ideology. The research question asked whether conservatism was negatively related to thinking Colbert was funny. In all the regressions, the demographic variables biological sex, race, (Caucasian/other), age, household income, political party affiliation (Democrat/other and Republican/other), and prior viewing of The Colbert Report were used as controls. As detailed above, approximately 58 percent of participants were female, the average age was $21(S D=2.23), 85$ percent were white, the mean household income was $\$ 50,001-75,000(S D=1.20)$, and the mean political party affiliation was "Independent" $(S D=1.22)$. Nearly 40 percent of the participants reported they "sometimes" watched The Colbert Report, 46 percent reported they "regularly" watched the show, and 9 percent "almost always" watched the show. Control variables were entered into block one of the regression equations, followed by the main independent variable, political ideology, in block two. Upon-entry and final unstandardized regression coefficients, standard errors, and $p$ values are reported for the control variables and political ideology in the five tables. In the text, the final unstandardized regression coefficients for political ideology are reported, with the standard errors and $p$ values for the four hypotheses and one research question.

\section{Post Hoc Statistical Power Analysis}

A post hoc power analysis was conducted using the software package, GPower (Faul and Erdfelder 1992). The sample size of 322 was used for the statistical power analyses and a 7 predictor variable equation was used as a baseline. The recommended effect sizes used for this assessment were as follows: small $\left(f^{2}=.02\right)$, medium $\left(f^{2}=.15\right)$, and large $\left(f^{2}=.35\right)$ (see Cohen 1977). The alpha level used for this analysis was $p<.05$. The post hoc analyses revealed the statistical power for this study was .40 for detecting a small effect, whereas the power exceeded .99 for the detection of a moderate to large effect size. Thus, there was more than adequate power (i.e., power $\geq .80$ ) at the moderate to large effect size level, but less than adequate statistical power at the small effect size level.

\section{Results}

\section{Processing Colbert's Political Statements}

Hypothesis 1 predicted a significant positive relationship between individuallevel political conservatism and perceptions that Colbert was targeting liberals through the use of his political comedy. The results supported the hypothesis, revealing that individual-level political conservatism was a significant predictor $(B=.377$, $S E=.077, p<.001)$ of perceptions that Colbert was using humor but truly meant 
Table 1

Regression Model Predicting the Perception That Colbert Is Genuine

\begin{tabular}{lcc}
\hline Variable & Upon Entry B $(S E)$ & Final B (SE) \\
\hline Block 1 & & \\
$\quad$ Constant & $6.073(1.079)$ & $5.290(1.052)$ \\
Biological sex (male coded high) & $-1.415(.226)^{* * *}$ & $-1.603(.221)^{* * *}$ \\
Race (white coded high) & $.160(.310)$ & $-.022(.301)$ \\
Party ID (Republican coded high) & $.056(.295)$ & $.140(.285)$ \\
Age & $.025(.046)$ & $.023(.045)$ \\
Household income & $.070(.094)$ & $-.037(.094)$ \\
Prior viewing of Colbert Report & $-.342(.125)^{* *}$ & $-.279(.121)^{*}$ \\
$R^{2}=.168$ & & $.377(.077)^{* * *}$ \\
Block 2 & & \\
Political ideology (conservative coded high) & & \\
$\Delta R^{2}=.063 * * *$ & & \\
Total $R^{2}=.231$ & & \\
\hline
\end{tabular}

Note: Unstandardized OLS regression Bs are reported (standard errors in parentheses). $N=297$. $* p<.05 ; * * p<.01 ; * * * p .001$.

what he said about liberals (Table 1). Thus, strong conservatives appear to have processed Colbert's statements (which targeted liberals) as representing how Colbert actually feels, an interpretation that most favored their own political ideology.

\section{Processing Colbert as Source}

Hypotheses 2 and 3 predicted that participants' political ideology would be significantly related to perceptions of Colbert's political party affiliation and ideology. Specifically, we expected that conservatives would be more likely to perceive Colbert as politically conservative (Hypothesis 2) and affiliated with the Republican Party (Hypothesis 3). The results for the perception of Colbert's political ideology regression (Hypothesis 2) revealed that individual-level political ideology was a significant predictor $(B=.119, S E=.043, p<.01)$ of perceptions of Colbert's ideology. Specifically, individual-level conservatism positively predicted perceptions that Stephen Colbert was politically conservative (Table 2). Similarly, results for the perception of Colbert's political party identity (Hypothesis 3 ) revealed that individuallevel conservatism marginally positively predicted perceptions that Stephen Colbert was a Republican $(B=.089, S E=.047, p=.06)$ (Table 3). Recalling the post hoc power analysis revealed low power for finding small effects, we believe that this finding would have a stronger level of significance given more statistical power.

Hypothesis 4 tested perceptions of how much Colbert liked/disliked liberals from political ideology. As predicted political conservatism was a positive, significant predictor $(B=.246, S E=.044, p<.001)$ of the perceptions that Colbert dislikes 
Table 2

Regression Model Predicting the Perception of Colbert as Politically Conservative

\begin{tabular}{lcc}
\hline Variable & Upon Entry B $(S E)$ & Final B (SE) \\
\hline Block 1 & & \\
$\quad$ Constant & $4.184(.584)$ & $3.938(.584)$ \\
Biological sex (male coded high) & $-.318(.122)^{* *}$ & $-.377(.123)$ \\
Race (white coded high) & $.050(.168)$ & $-.007(.167)$ \\
Party ID (Republican coded high) & $-.086(.160)$ & $-.060(.158)$ \\
Age & $-.042(.025)$ & $-.043(.025)$ \\
Household income & $-.031(.051)$ & $-.065(.052)$ \\
Prior viewing of Colbert Report & $-.047(.068)$ & $-.027(.067)$ \\
$R^{2}=.043$ & & \\
Block 2 & & \\
Political ideology (conservative coded high) & $.119(.043)^{* *}$ & \\
$\Delta R^{2}=.024 * *$ & & \\
Total $R^{2}=.067$ & & \\
\hline
\end{tabular}

Note: Unstandardized OLS regression Bs are reported (standard errors in parentheses). $N=297$. $* * p<.01$.

Table 3

Regression Model Predicting the Perception of Colbert as Republican

\begin{tabular}{lcc}
\hline Variable & Upon Entry B (SE) & Final B (SE) \\
\hline Block 1 & & \\
Constant & $4.276(.635)$ & $4.091(.640)$ \\
Biological sex (male coded high) & $-.204(.133)$ & $-.249(.135)$ \\
Race (white coded high) & $.045(.183)$ & $.002(.183)$ \\
Party ID (Republican coded high) & $.078(.174)$ & $.098(.173)$ \\
Age & $-.044(.027)$ & $-.044(.027)$ \\
Household income & $-.021(.073)$ & $-.046(.057)$ \\
Prior viewing of Colbert Report & $-.154(.073)^{*}$ & $-.139(.074)$ \\
$R^{2}=.040$ & & \\
Block 2 & & \\
Political ideology (conservative coded high) & $.113(.044) \dagger$ & \\
$\Delta R^{2}=.012 \dagger$ & & \\
Total $R^{2}=.052$ & & \\
\hline
\end{tabular}

Note: Unstandardized OLS regression Bs are reported (standard errors in parentheses). $N=297$. $\dagger p<.06 . * p<.05$.

liberals. This set of results supports the idea that conservatives not only processed the messages as targeting liberals, but also processed the source as being conservative, Republican, and disliking liberals. By contrast, liberals perceived Colbert as just kidding and did not perceive the source as conservative, Republican, or disliking liberals. 


\section{Perception of Colbert as Humorous}

Research Question 1 asked whether a significant negative relationship between political conservatism and perceptions of Colbert as funny existed. Results indicated that conservatism did not significantly predict perceptions of Colbert as funny $(B=.017, S E=.044, p>.1)$. It appears that both groups find Colbert equally funny suggesting that both sides see the humor yet differ in their perceptions of what or who is being parodied and/or satirized in the late-night comedy show.

\section{Post Hoc Analysis}

As expected, the results confirm that biased processing occurs in response to Colbert's ambiguous deadpan satire and that such processing is serving to polarize viewers. Although it may simply be that Colbert serves to reinforce existing viewpoints that strengthen attitudes and polarize the electorate, we were interested in whether perceptions of Colbert's attitudes also mediated the relationship between individual-level political ideology and political attitudes. As such we conducted a post hoc analysis of the attitudinal data collected in this study. Because results indicated that biased processing was occurring, we expected that such bias also influenced how individuals perceive Colbert's political attitudes such that strong conservatives would hold significantly more perceptions than strong liberals that Colbert's personal attitudes were conservative Republican. Furthermore, we predicted that people who thought Colbert had a conservative Republican attitude on a political issue would be significantly more likely to report their own attitude on the same issue as consistent with a conservative Republican viewpoint (e.g., self-reporting attitudes consistent with their perception of Colbert's opinion on the same issue). Thus, we expected individual-level perceptions of Colbert's personal opinion mediated the relationship between their own political ideology and their self-reported political opinion.

Using the topic of embedded journalists discussed in the video clip, we found a main effect where individual conservatism was a positive significant predictor of individual-level favorable opinion regarding the military's use of embedded journalists in the Iraq war $(B=.112, S E=.038, p<.01)$. Additionally, individual-level conservatism was a positive predictor of perceptions that Colbert personally favored embedded journalists in the Iraq War $(B=.109, S E=.038, p<.01)$, and perceptions of Colbert's opinion regarding embedded journalists positively predicted individuallevel opinion regarding embedded journalists $(B=.493, S E=.057, p<.001)$. When the final dependent variable (individual-level attitudes regarding embedded journalists) was entered into the model, the main effect (predicting individual-level attitudes from individual-level political ideology) was no longer significant $(B=.011, S E=$ $.037, p>.1$ ), demonstrating a fully mediated process. In summary, we found that individual-level attitudes regarding embedded journalists were fully mediated by 
perceptions of Colbert's opinion regarding embedded journalists. From these results, it appears that perceptions of ambiguous sources such as Colbert do influence individually held political attitudes and that biased processing has an indirect effect on individual-level political attitudes.

\section{Discussion}

This study moves beyond simple media effects as it examines a process of how people negotiate the ambiguity of deadpan satire in political entertainment. Specifically, we have outlined a cognitive process in which individuals who consume ambiguous political messages from ambiguous sources (e.g., Stephen Colbert) in late-night comedy interpret the messages in ways that support and/or reinforce personally held political beliefs. Results indicate that the ambiguous deadpan satire offered by Stephen Colbert in The Colbert Report is interpreted by audiences in a manner that best fits with their individual political beliefs. While common wisdom might suggest that this is simply comedy and people should "get the joke," this study demonstrates that such assumptions do not seem to hold true when the source is also ambiguous, offering no external cues to guide individuals' message processing.

Of particular interest was the finding that no significant difference existed between conservatives and liberals regarding how funny Stephen Colbert was (Research Question 1). The results indicate that both liberals and conservatives recognize the comedy, but see something totally different in terms of intended message and source. While audiences do comprehend the humor, there are marked differences in who conservatives and liberals perceive as joke targets and how they perceive Colbert's political affiliation, ideology, and attitudes. Considering this in terms of political entertainment, the major point this study raises is that while both groups of people know it is comedy and presumably watch it to be entertained, there are stark differences in how they see the comedy, who they think is being satirized, and how those differences polarize the electorate by reinforcing their own set of beliefs as valid and the opposing set of beliefs as laughable.

These results suggest that assumptions previously held regarding the role of latenight comedy and political satire might not be accurate and that perception plays a significant role in way audiences interpret the comedy. Extending this to other forms of political satire such as late-night comedy programs, stand-up comedians, animation, movies, and political cartoons, we must consider the possibility that these political messages are influencing audiences in differing ways and that audience perceptions play a much stronger role that previously thought. More importantly, political satire may not affect people in the way that it has historically been assumed (i.e., satire has been feared and banned because it is seen as a powerful force, Feinberg 1967).

It is quite possible that this type of political entertainment is processed with biases and reinterpreted in ways that serve to reinforce political viewpoints. It 
appears from these results that biased processing serves a function of reinforcing individually held political beliefs and attitudes. Thus, when conditions for biased processing exist (e.g., Colbert's deadpan satire) polarization is likely to result. As individuals on each side of the political issue interpret the source as targeting the opposition and agreeing with their own viewpoint, the two opposing sides are likely to strengthen their own position as "the correct position," thereby leading to a deeper divide between the two groups. This type of polarization effect has been found to have negative consequences for democracy (e.g., Cigler and Getter 1977). While it is important to consider that much of the political satire offered by comedians includes contextual cues to aid audiences in interpreting the messages, it is equally important to note that when biased processing takes place the effects of such processing will likely play a significant role in strengthening attitudes (Krosnick and Petty 1995).

The post hoc analysis revealed the mediating role that biased perceptions of an ambiguous source can play between individual political ideology and individual political attitudes. While this was a cursory analysis and more work in the area of biased processing and political attitudes is needed before conclusions can be reached, it does appear that conservative's biased perceptions of Colbert's attitudes had a significant influence on their individual attitudes about the same attitude object. Strong conservatives were significantly more likely to perceive Colbert as having personal political attitudes that were consistent with their own. These biased perceptions of Colbert's personal attitudes were a strong predictor of individual attitudes, such that the individuals' attitudes were significantly more likely to remain consistent with perceptions of Colbert's attitude. In sum, conservatives' personal attitudes were influenced by their perception of Colbert's attitude, and relatively strong conservatives were more likely to report attitudes consistent with their perceptions of Colbert's attitude. Although we are far from suggesting that perceptions of Colbert's attitudes are driving individual attitudes, we can conclude that biased perceptions are playing an important mediating role in this process that merits much more investigation. From these analyses, it appears that biased processing is serving two potential roles: attitude formation and strengthening. Thus, we suggest that future studies focus on these two roles of biased processing in the study of political entertainment and attitudes.

In addition to examining the potential influence of biased processing on attitudes, future studies should also examine biased message processing and long-term recall of the satirist's political position. For example, do people who watch late-night political comedy and consume ambiguous political messages from The Colbert Report have accurate recall of Colbert's political viewpoint at a later time? Or, is there a potential sleeper effect that should be examined? It might be possible that even those who accurately identified the satire and understood Colbert was joking experience difficulty in accurately recalling the comedian's political messages. Do people who consume satire store and recall the satirical form of the message or do they store and recall the 
negated and reinterpreted underlying meaning of the satire? Another possibility is that audiences recall Colbert's statements or viewpoints at a later time without remembering who said them. In this case, the source fades over time in memory, yet the content of the message remains (Frymier and Nadler 2007). With satire, however, the obvious question is whether the individuals recall the satirical statements literally. If so, it is possible that people who remember what was said without recalling who said it will also forget that it was a joke. If this happens, people may be more likely to assume that message was true. It would be quite interesting to replicate this study using a delayed posttest aimed at illuminating the long-term effects of consuming political satire and unpacking some of these complex cognitive processes.

More generally, this study enumerates the importance of political satire in popular culture and the perceived role that satire plays in the political landscape. Recall that governments and institutions have banned political satire on the grounds that it challenges and pushes the status quo (Feinberg 1967). However, going back to Vidmar and Rokeach's (1974) study on prejudice and All in the Family, one must realize this assumption is not always correct. It is noteworthy that the producer of All in the Family, Norman Lear, regarded the show as an effective weapon against bigotry and racism. Lear reasoned that audiences would see that Archie Bunker had convoluted logic and his counterpart, liberal son-in-law Mike, was the one who made sense. Instead, the show may have been perceived by audiences as condoning and even encouraging prejudice. This study's findings can be understood in the same light as the All in the Family study. Because both groups perceive the messages and the source as supporting their own political views, it seems plausible that both liberals and conservatives could use Stephen Colbert and The Colbert Report as a showcase for why their political viewpoints are correct. Perhaps that is why 2008 Republican presidential candidate Mike Huckabee made repeated appearances on the show and thanked Stephen Colbert for giving him the "Colbert bump," which he claimed made a significant positive impact in his bid for the White House (ColbertNation.com 2007). Another example of this was seen when Stephen Colbert was invited as the host of the 2006 White House Correspondents Dinner with the belief that he was a proconservative political comedian. Colbert is often quoted by both liberals and conservatives (e.g., Mike Huckabee thanked Colbert during his bid for the Republican presidential nomination supporting him) as lending support to their side of the debate. It would be interesting to use such quotes in a future study to examine whether individuals agree that Colbert intended those statements as support.

Finally, while this study reveals several interesting insights regarding the role of political ideology in processing political satire, it was only a beginning. There were a few constraints that need addressed through replication and additional research. The most pressing constraint was the lack of variance in the party affiliation measure. In our sample, it seemed that these college students may not have solidified their political affiliations, which inhibited our ability to use party affiliation as our main independent variable. Although we were able to use political ideology, we suggest a 
replication of this study using a noncollege adult sample. However, we are confident that the results remain valid and we suspect that using affiliation over ideology will likely result in even stronger effects.

The above examples provide just a few of the possible areas to explore in future research. There is much work to be done regarding political comedy and message processing, most of which should extend beyond the domain of late night to include other common outlets for ambiguous political communication. In short, this study raises questions about the influence of shows that parody and satirize the political actors, groups, and belief systems such as South Park, The Simpsons, and Saturday Night Live, suggesting that regardless of joke intent people will potentially see what they want to see. Finally, this set of findings offers evidence that political satire offers a complex set of messages that play a significant role in the attitude formation and strengthening process. As previously discussed, it appears that perceptions are a key variable that political entertainment scholars should include in studies aimed at understanding the persuasive influence of political entertainment on individual-level political attitudes and opinions.

\section{References}

Balcetis, Emily, and David Dunning. 2006. "See What You Want to See: Motivational Influences on Visual Perception." Journal of Personality and Social Psychology 91(4):612-25.

Baym, Geoffrey. 2005. "The Daily Show: Discursive Integration and the Reinvention of Political Journalism" Political Communication 22(3):259-76.

Beck, Paul Allen. 1992. Party Politics in America. New York: Harper Collins.

Bem, Daryl J. 1972. "Self-Perception Theory." In Advances in Experimental Social Psychology, ed. L. Berkowitz. New York: Acedemic Press.

Brewer, Marilynn B. 1991. "The Social Self: On Being the Same and Different at the Same Time." Personality and Social Psychology Bulletin 17(5):475-82.

Busselle, Rick W., and Bradley S. Greenberg. 2000. "The Nature of Television Realism Judgments: A Reevaluation of Their Conceptualization and Measurement." Mass Communication \& Society 3(2\&3):249-68.

Campbell, Angus, Philip E. Converse, Warren E. Miller, and Donald E. Stokes. 1960. The American Voter. Chicago: The University of Chicago Press.

Carsey, Thomas M., and Geoffrey C. Layman. 2006. "Changing Sides or Changing Minds? Party Identification and Policy Preferences in the American Electorate." American Journal of Political Science 50(2):464-77.

Cigler, Allan J., and Russell Getter. 1977. "Conflict Resolution in the Post-Election Period: A Test of the Depolarization Thesis." The Western Political Quarterly 30:363-376.

Cohen, Jonathan. 1977. Statistical Power Analysis for the Behavioral Sciences (revised edition). New York: Academic Press.

ColbertNation.com. 2007. Mike Huckabee | August 16, 2007 -Andrew Keen | ColbertNation.com. Retrieved Sept. 24, 2008. <http://www.colbertnation.com/the-colbert-report-videos/91746/august-16-2007/mike-huckabee> .

ComedyCentral.com. 2008. Amy Goodman Pt. 1. The Colbert Report. Retrieved Feb. 12, 2008. <http://www .comedycentral.com/colbertreport/videos.jhtml?videoId $=76345>$.

ComedyCentral.com. 2007. Anderson Cooper. The Colbert Report. Retrieved Feb. 18, 2008. $<$ http://www.comedycentral.com/colbertreport/videos.jhtml?videoId=123811>. 
Delli Carpini, Michael X., and Bruce A. Williams. 1994. "Methods, Metaphors, and Media Research: The Uses of Television in Political Conversation." Communication Research 21(6):782-812.

Faul, Franz, and Edgar Erdfelder. 1992. "GPOWER: A Priori, Post-hoc, and Compromise Power Analyses for MS-DOS" [Computer program]. Bonn: Bonn University, Department of Psychology. Retrieved Apr. 1, 2005. <http://www.psycho.uniduesseldorf.de/aap/projects/gpower>.

Feinberg, Leonard. 1967. Introduction to Satire. Ames, IA: The Iowa State University Press.

Festinger, Leon. 1957. A Theory of Cognitive Dissonance. Oxford: Stanford University Press.

Frymier, Ann B., and Marjorie K. Nadler. 2007. Persuasion: Integrating Theory, Research, and Practice. Dubuque, IA: Kendall/Hunt Publishing Company.

Holbert, R. Lance, Jennifer L. Lambe, Anthony D. Dudo, and Kristin A. Carlton. 2007. "Primacy Effects of the Daily Show and National TV News Viewing: Young Viewers, Political Gratifications, and Internal Political Self-Efficacy." Journal of Broadcasting \& Electronic Media 51(1):20-38.

Holbert, R. Lance, Dhavan V. Shah, and Nojin Kwak. 2003. "Political Implications of Prime-Time Drama and Sitcom Use: Genres of Representation and Opinions Concerning Women's Rights." Journal of Communication 53(1):45-60.

Holbert, R. Lance, Dhavan V. Shah, and Nojin Kwak. 2004. "Fear, Authority, and Justice: The Influence of TV News, Police Reality, and Crime Drama Viewing on Endorsements of Capital Punishment and Gun Ownership." Journalism \& Mass Communication Quarterly 81(2):343-63.

Holbrook, R. Andrew, and Timothy Hill. 2005. "Agenda-Setting and Priming in Prime Time Television: Crime Dramas as Political Cues." Political Communication 22(3):277-95.

Hovland, Carl I. 1951. "Human Learning and Retention." In Handbook of Experimental Psychology, ed. Stanley Smith Stevens. New York: Wiley.

Krosnick, Jon and Richard Petty. 1995. "Attitude Strength: An Overview." In Attitude Strength: Antecedents and Consequences, eds. Richard Petty, and Jon Krosnick. Mahwah, NJ: Lawrenece Erlbaum Associates.

Kunda, Ziva. 1990. "The Case for Motivated Reasoning." Psychological Bulletin 108(3):480-98.

LaMarre, Heather L., and Michael McCluskey. 2007, November. "Beyond The Daily Show: Examining the Show Host Personas of Jon Stewart and Stephen Colbert." Presented at the Midwest Association for Public Opinion Research. Chicago, IL.

Leary, Mark R., and Roy F. Baumeister. 2000. "The Nature and Function of Self-Esteem: Sociometer Theory." In Advances in Experimental Social Psychology, ed. Mark P. Zanna. San Diego, CA: Academic Press.

Long, George, and Thomas Toppino. 2004, "Enduring Interest in Perceptual Ambiguity: Alternating Views of Reversible Figures. Psychological Bulletin 13:748-68.

McLeod, Douglass, Gerald Kosicki, and Jack McLeod. 2002. Resurveying the Boundaries of Political Communication Effects. In Media Effects: Advances in Thoery and Research. 2nd Edition. ed. Jennings Bryant and Dolf Zillmann. Mahwah, NJ: Lawrence Erlbaum Associates.

Pfaff, Kerry L., and Raymond W. Gibbs Jr. 1997. "Authorical Intentions in Understanding Satirical Texts." Poetics 25:45-70.

RushLimbaugh.com. 2008. Global Warming Hoax is in Retreat. Retrieved Sept. 24, 2008. <http://www .rushlimbaugh.com/home/daily/site_050908/content/01125113.guest.html>.

Shrum, L.J. 2002. "Media Consumption and Perceptions of Social Reality: Effects and Underlying Processes." In Media Effects: Advances in Theory and Research, eds J. Bryant, and D. Zillmann. Mahwah, NJ: Lawrence Erlbaum Associates.

Simpson, Paul. 2003. On the Discourse of Satire. Philadelphia, PA: John Benjamins Publishing Company.

Tajfel, Henri, and John C. Turner. 1986. "The Social Identity Theory of Intergroup Behavior." In Psychology of Intergroup Relations, eds. Stephen Worchel and William G. Austin. Chicago: Nelson-Hall.

Tourangeau, Roger, Lance J. Rips, and Kenneth Rasinski. 2000. The Psychology of Survey Response. New York: Cambridge.

Vallone, Robert P., Lee Ross, and Mark R. Lepper. 1985. "The Hostile Media Phenomenon: Biased Perception and Perceptions of Media Bias in Coverage of the Beirut Massacre." Journal of Personality and Social Psychology 49(3):577-85. 
Vidmar, Neil, and Milton Rokeach. 1974. “Archie Bunker's Bigotry: A Study in Selective Perception and Exposure." Journal of Communication 24:36-47.

Young, Dannagal G. 2004. "Late-Night Comedy in Election 2000: Its Influence on Candidate Trait Ratings and the Moderating Effects of Political Knowledge and Partisanship." Journal of Broadcasting \& Electronic Media 48(1):1-22.

Young, Dannagal G. (2008). "The Privileged Role of the Late-Night Joke: Exploring Humor's Role in Disrupting Argument Scrutiny." Media Psychology 11(1):119-42.

Young, Dannagal G., and Russell M. Tisinger. (2006). "Dispelling Late-Night Myths: News Consumption among Late-Night Comedy Viewers and the Predictors of Exposure to Various Late-Night Shows." Harvard International Journal of Press/Politics 11(3):113-34.

Heather L. LaMarre is an assistant professor at the University of Minnesota's School of Journalism and Mass Communication, where she studies political communication, strategic communication, and entertainment media. LaMarre's research examines the persuasive influence of political entertainment media on individual-level attitudes and opinions. Address: Heather L. LaMarre, School of Journalism and Mass Communication, 111 Murphy Hall, 206 Church Street S.E., Minneapolis, MN 55455; phone: 614-8432881; e-mail: HLaMarre@gmail.com.

Kristen D. Landreville is a PhD student at the School of Communication at The Ohio State University, where she studies political communication and entertainment media. Her specific area of research concerns the process of emotion and engagement in political entertainment, and the role that political entertainment plays in the interpersonal communication of American political life. Address: School of Communication, The Ohio State University, 3016 Derby Hall, 154 North Oval Mall, Columbus, OH 43210; phone: 614-356-3464; e-mail: Landreville.1@osu.edu.

Michael A. Beam is a PhD student at the School of Communication at The Ohio State University, where he studies political communication and new media. Address: School of Communication, The Ohio State University, 3016 Derby Hall, 154 North Oval Mall, Columbus, OH 43210; phone: 614-915-5532; e-mail: beam.33@osu.edu. 